\title{
Quality of Life, Psychological Well-Being and Depression among Elderly: a Co relational Study
}

\author{
Nibedita Jena ${ }^{1}$, Shraddha Das ${ }^{2}$ and Himansu Kumar Deo ${ }^{3}$ \\ ${ }^{1}$ Department of Psychology, Ravenshaw University, India \\ ${ }^{2}$ Department of Clinical Psychology, Udayanath College of Science and Technology, India \\ ${ }^{3}$ Department of Clinical Psychology, Udayanath College of Science and Technology, India
}

Submission: November 14, 2017; Published: February 01, 2018

*Corresponding author: Nibedita Jena, Department of Psychology, Ravenshaw University, Cuttack-753003, India, Email: drnjena@gmail.com

\begin{abstract}
Human culture may be viewed in terms of a number of interacting component systems [1], each of which caters to a basic need. First and foremost culture is a belief system; there is invariably some religious commitment to a higher order of presumed powers or conjured beings. There is a subtle hint of stupidity as a common element which unifies culture into a disintegrating whole. For the past two hundred years, social scientists have been trying to impose some order of logic on the actions and interrelationships of these systems. Perhaps it is time to consider the very real possibility that such order and logic are, like astrological figures, invented and both the systems and their interactions are illogical, inconsistent and maladaptive to the point that culture may be characterized as stupid.
\end{abstract}

Keywords: Human culture; Religious commitment; Stupidity; Social scientists; Illogical

\section{Introduction}

Aging is an inevitable developmental phenomenon bringing along a number of changes in the physical, psychological, and hormonal and the social conditions. Old age has been viewed, as problematic period of one's life and this is correct to same extent. The aged become increasingly dependent on others. As man grows, his reduced activities, income and consequent decline in the position of the family and society makes his life more vulnerable. Older people are, therefore, in need of vital support their overall quality of life. Depression is one of the most common psychological conditions during the normal course of life with so much of losses and disappointments. Depression in old age is quite common and complex. Depression in old age creates many problems in carrying out activities of daily living. Being left alone often prevents many older persons from enjoying life. Psychological well-being studied extensively as there is a need to improve the state of mental conditions of people. Quality of life is the general wellbeing of individuals [1-4].

Psychological wellbeing and quality of life both are necessary factors for decreasing the depression rate among elderly. As psychological wellbeing, satisfaction in life, quality of life and happiness among elderly increases their depression rate and mental illness also decreases. In the present study we made a co relational study to find out the quality of life, psychological wellbeing and depression among elder people.

\section{Objective}

a. To study the quality of life, psychological well-being and depression among the elderly in an urban set up.

b. To study the relationship between quality of life, psychological wellbeing and depression.

c. To study the effect of gender and socioeconomic status on the depression of the elderly moderated by quality of life and psychological wellbeing.

\section{Sample}

The sample consisted of 120 subjects randomly selected from the urban population of Bhubaneswar. The method of sampling was stratified purposive sampling selecting 40 subjects each from the high, middle and low SES status groups. The socioeconomic status of the subject was determined by Kupuswamy SES scale. In each of the SES groups, equal number of men and women will be included in the study [5].

\section{Test}

Four instruments were to measure the four variables in the proposed study. All these four measures are popular instruments with established psychometric properties. 
a. Kupuswamy's Socioeconomic Status Scale (adapted version) will be used to assess the SES status of the subjects. The scale consists of 7 items each to measure the education score and income score of the subjects to divide them into high, middle and low SES groups.

b. McGill Quality of Life Questionnaire consisting of 15 items each to be responded by the subjects on a 10 point scale. Higher the score in the scale better is the quality of life.

c. Ryff scale for psychological wellbeing consists of 42 items to measure 6 dimensions of psychological wellbeing namely; Self- acceptance, Positive relations with others, Autonomy, Environmental mastery, Purpose in life, and personal growth.

d. Beck's Depression Inventory consisting of 21 items will be used to measure the level of depression of the subjects.

\section{Procedure}

The investigator contacted some social organizations, religious institutes, senior citizen clubs and residential apartments to find out the sample for the study. Each subject was personally contacted and requested to cooperate and participate in the research. The investigator prepared a booklet including all the tests. Because, most of the subjects had adequate educational qualifications, the booklet was handed over to them to help them complete the tests in their convenient time. As senior citizens, they were very cooperative and sincere in responding to the test. The investigator collected the filled in booklet from them [6,7].

\section{Results}

Keeping in view the objectives of the present study the data were analysed by means of two-way analysis of variance and co relational analysis. The subjects were classified for gender as men and women and then in respect of their Socio-economic status as high, medium and low. The results have been presented in separate tables [8].

\section{Quality of life}

The range of scores of subjects shown that women have higher range of variance in the quality of life compared to men. From the result Table 1 it was found that there is no significant main effect of gender was observed with respect to quality of life between men and women independent of the factor of SES. On the other hand, the main effect of SES is found to be significant to suggest that among the urban elderly, SES is a major factor for determining their quality of life. The interaction effect between gender and SES is not also significant to precisely point to a clear role of SES in determining the quality of life of the urban elderly [9].

Table 1: Two-way ANOVA (Gender X SES) on quality of life of urban elderly.

\begin{tabular}{|c|c|c|c|c|c|c|}
\hline Sources & SS & df & MS & \multicolumn{3}{|c|}{$\mathbf{F}$} \\
\hline Gender & 132.3 & 1 & 132.3 & \multicolumn{3}{|c|}{0.58} \\
\hline SES & 6097.27 & 2 & 3048.64 & \multicolumn{3}{|c|}{$13.11^{* *}$} \\
\hline Gender X SES & 1023.8 & 2 & 511.9 & \multicolumn{3}{|c|}{2.23} \\
\hline Error & 26112.1 & 114 & 229.05 & & & \\
\hline \multicolumn{4}{|c|}{ Men } & \multicolumn{3}{|c|}{ Women } \\
\hline & High & Medium & Low & High & Medium & Low \\
\hline Mean & 78.75 & 77.9 & 69 & 88.15 & 79.7 & 64.1 \\
\hline SD & 16.68 & 17.09 & 13.34 & 18.21 & 13.08 & 10.02 \\
\hline
\end{tabular}

${ }^{* *} \mathrm{P}<.01$

\section{Psychological wellbeing}

The psychological wellbeing of the subjects were measured in six dimensions namely autonomy, environmental mastery, personal growth, positive relations, purpose in life and selfacceptance. The results of Analysis of Variance for the attribute of Autonomy are reported in Table 2. It observed from the means that in high and middle SES groups, men have higher autonomy than women while in low SES groups. Further, autonomy of men decreases with decreasing status in SES while for women autonomy increases for middle and low SES groups. However, the results of ANOVA show significant main effects of both gender and SES status and the interaction effect is not found significant. Hence it may be derived that in the population of urban elderly, women are given less autonomy and particularly among the high SES groups; women have less freedom and autonomy. On the other hand, men have better autonomy compared to women in both high and middle SES groups [10]. 


\section{Global Journal of Intellectual \& Developmental Disabilities}

Table 2: Two-way ANOVA (Gender X SES) on psychological well-being of autonomy of urban elderly.

\begin{tabular}{|c|c|c|c|c|c|c|}
\hline Sources & SS & Df & \multicolumn{2}{|c|}{ MS } & \multicolumn{2}{|c|}{$\mathbf{F}$} \\
\hline Gender & 476.54 & 1 & \multicolumn{2}{|c|}{476.54} & \multicolumn{2}{|c|}{$12.48^{* *}$} \\
\hline SES & 2944.31 & 2 & \multicolumn{2}{|c|}{1472.16} & \multicolumn{2}{|c|}{$38.57^{* *}$} \\
\hline Gender X SES & 185.38 & 2 & \multicolumn{2}{|c|}{92.93} & \multicolumn{2}{|c|}{2.43} \\
\hline Error & 4351.67 & 114 & \multicolumn{2}{|c|}{38.17} & & \\
\hline \multicolumn{4}{|c|}{ Men } & \multicolumn{3}{|c|}{ Women } \\
\hline & High & Medium & Low & High & Medium & Low \\
\hline Mean & 22.65 & 19.34 & 13.19 & 12.56 & 14.45 & 13.11 \\
\hline SD & 3.51 & 3.69 & 2.47 & 2.96 & 2.84 & 3.15 \\
\hline
\end{tabular}

${ }^{* *} \mathrm{P}<.01$

Table 3: Two-way ANOVA (Gender X SES) on psychological well-being in environmental mastery of urban elderly.

\begin{tabular}{|c|c|c|c|c|c|c|}
\hline Sources & SS & Df & \multicolumn{2}{|c|}{ MS } & \multicolumn{2}{|c|}{$\mathbf{F}$} \\
\hline Gender & 1123.39 & 1 & \multicolumn{2}{|c|}{1123.39} & \multicolumn{2}{|c|}{$33.09 * *$} \\
\hline SES & 970.44 & 2 & \multicolumn{2}{|c|}{485.82} & \multicolumn{2}{|c|}{$14.30^{* *}$} \\
\hline Gender X SES & 227.36 & 2 & \multicolumn{2}{|c|}{113.68} & \multicolumn{2}{|c|}{3.34} \\
\hline Error & 3870.81 & 114 & \multicolumn{2}{|c|}{33.95} & & \\
\hline \multicolumn{5}{|c|}{ Men } & \multicolumn{2}{|c|}{ Women } \\
\hline & High & Medium & Low & High & Medium & Low \\
\hline Mean & 21.46 & 23.44 & 26.57 & 18.54 & 19.47 & 21.77 \\
\hline SD & 3.55 & 2.89 & 3.36 & 2.54 & 2.81 & 2.83 \\
\hline
\end{tabular}

${ }^{* *} \mathrm{P}<.01$

Table 4: Two-way ANOVA (Gender X SES) on Psychological Well-being in Personal Growth of urban elderly.

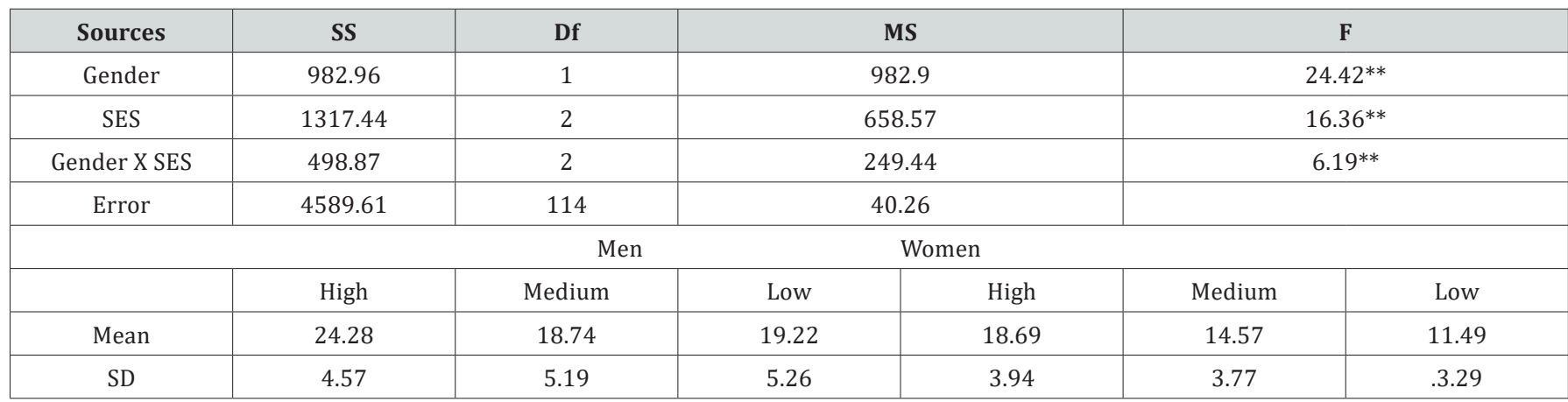

${ }^{* *} \mathrm{P}<.01$

The results of two-way ANOVA with respect to Environmental Mastery are presented in Table 3. From the result of two-way ANOVA it was found that the main effect of gender is found significant in favour of men about environmental mastery. Similarly, the main effect of SES is found significant in favour of the low SES groups to conclude that SES status is negatively impacts mastery of the environment of the urban elderly population. The interaction effect is not significant to point out the results of the main effects are clearly justifiable. The results of two-way ANOVA of the subjects in personal growth and the corresponding means are reported in Table 4. From the results of two-way ANOVA it was found that the main effect of gender, SES and the interaction effect are all significant. . Hence it may be derived that personal growth as a psychological wellbeing among the urban elderly is significantly influenced by gender in

favour of men, by SES status in favour of high SES groups and also by an interaction of these two variables.

The results of two-way ANOVA of the subjects in case of positive relation and their corresponding means are reported in Table 5. The results of ANOVA show significant main effects for both gender and SES but the interaction is not significant. Hence, in general it may be said that men are better in maintaining positive relations and middle class men and women are better in this skill compared to both low and high SES groups. The results of ANOVA of the subjects in case of purpose in life and corresponding means are presented in Table 6 . The results of ANOVA pointed to the significant main effects of both gender and SES while the interaction effect is not significant. Hence it may be derive that some purpose in life continues to be a part 


\section{Global Journal of Intellectual \& Developmental Disabilities}

of living among urban elderly and compared to women, men are groups are found to have maintained greater purpose in life better in this psychological wellbeing. Further, the middle class compared to both the high and low SES groups.

Table 5: Two-way ANOVA (Gender X SES) on psychological well-being in positive relationship of urban elderly.

\begin{tabular}{|c|c|c|c|c|c|c|}
\hline Sources & SS & Df & \multicolumn{2}{|c|}{ MS } & \multicolumn{2}{|c|}{$\mathbf{F}$} \\
\hline Gender & 793.68 & 1 & \multicolumn{2}{|c|}{793.68} & \multicolumn{2}{|c|}{$14.37^{* *}$} \\
\hline SES & 1206.55 & 2 & \multicolumn{2}{|c|}{603.28} & \multicolumn{2}{|c|}{$10.92^{* *}$} \\
\hline Gender X SES & 373.52 & 2 & \multicolumn{2}{|c|}{186.76} & \multicolumn{2}{|c|}{3.38} \\
\hline Error & 6294.77 & 114 & \multicolumn{2}{|c|}{55.22} & & \\
\hline \multicolumn{5}{|c|}{ Men } & \multicolumn{2}{|c|}{ Women } \\
\hline & High & Medium & Low & High & Medium & Low \\
\hline Mean & 17.65 & 23.11 & 22.24 & 18.38 & 19.56 & 15.81 \\
\hline SD & 3.36 & 3.94 & 4.51 & 3.32 & 2.89 & 3.54 \\
\hline
\end{tabular}

${ }^{* *} \mathrm{P}<.01,{ }^{*} \mathrm{P}<.05$

Table 6: Two-way ANOVA (Gender X SES) on psychological well-being in purpose in life of urban elderly.

\begin{tabular}{|c|c|c|c|c|c|c|}
\hline Sources & SS & df & \multicolumn{2}{|c|}{ MS } & \multicolumn{2}{|c|}{$\mathbf{F}$} \\
\hline Gender & 621.11 & 1 & \multicolumn{2}{|c|}{621.11} & \multicolumn{2}{|c|}{$14.04^{* *}$} \\
\hline SES & 370.47 & 2 & \multicolumn{2}{|c|}{185.23} & \multicolumn{2}{|c|}{$4.18^{*}$} \\
\hline Gender X SES & 170.37 & 2 & \multicolumn{2}{|c|}{85.19} & \multicolumn{2}{|c|}{1.93} \\
\hline Error & 502.54 & 114 & \multicolumn{2}{|c|}{44.23} & & \\
\hline \multicolumn{5}{|c|}{ Men } & \multicolumn{2}{|c|}{ Women } \\
\hline & High & Medium & Low & High & Medium & Low \\
\hline Mean & 18.45 & 19.23 & 18.11 & 16.31 & 14.96 & 14.33 \\
\hline SD & 3.56 & 3.12 & 2.89 & 4.18 & 4.36 & 3.97 \\
\hline
\end{tabular}

${ }^{* *} \mathrm{P}<.01,{ }^{*} \mathrm{P}<.05$

Table 7: Two-way ANOVA (Gender X SES) on psychological well-being in self-acceptance of urban elderly.

\begin{tabular}{|c|c|c|c|c|c|c|}
\hline Sources & SS & df & \multicolumn{2}{|c|}{ MS } & \multicolumn{2}{|c|}{$\mathbf{F}$} \\
\hline Gender & 872.55 & 1 & \multicolumn{2}{|c|}{872.55} & \multicolumn{2}{|c|}{$20.42^{* *}$} \\
\hline SES & 851.40 & 2 & \multicolumn{2}{|c|}{425.70} & \multicolumn{2}{|c|}{$9.96^{* *}$} \\
\hline Gender X SES & 257.51 & 2 & \multicolumn{2}{|c|}{128.76} & \multicolumn{2}{|c|}{3.01} \\
\hline Error & 4870.48 & 114 & \multicolumn{2}{|c|}{42.72} & & \\
\hline \multicolumn{5}{|c|}{ Men } & \multicolumn{2}{|c|}{ Women } \\
\hline & High & Medium & Low & High & Medium & Low \\
\hline Mean & 22.55 & 20.18 & 18.34 & 24.67 & 24.51 & 21.39 \\
\hline SD & 3.17 & 3.54 & 2.95 & 2.73 & 3.11 & 3.28 \\
\hline
\end{tabular}

${ }^{* *} \mathrm{P}<.01$

The results of ANOVA of the subjects in self acceptance and corresponding means are presented in Table 7. The result of ANOVA show significant main effects for both gender and SES

but the interaction effect is not significant. Hence, it may be concluded that self acceptance is influenced by both gender and SES status. 


\section{Global Journal of Intellectual \& Developmental Disabilities}

\section{Depression}

The level of depression of the subjects was also measured by the Beck's depression Inventory. The means and standard deviations for all six groups of subjects are presented in Table 8. As observed from the means, most of the urban elderly have some level depression which range between mild mood disturbances to borderline depression. As indicated by means women are more depressed than men, particularly in high and middle SES groups. In the low SES groups both men and women are less depressed. The results of ANOVA presented in Table 8 also showed significant main effects of both gender and SES on depression. Hence, it may be concluded that women are more depressed than men and urban elderly in the high and middle SES classes are more depressed compared to their counterparts in low SES groups.

Table 8: Two-way ANOVA (Gender X SES) on psychological beck's depression measure of urban elderly.

\begin{tabular}{|c|c|c|c|c|c|c|}
\hline Sources & SS & df & \multicolumn{2}{|c|}{ MS } & \multicolumn{2}{|c|}{$\mathbf{F}$} \\
\hline Gender & 301.53 & 1 & \multicolumn{2}{|c|}{301.53} & \multicolumn{2}{|c|}{$9.59^{* *}$} \\
\hline SES & 400.41 & 2 & \multicolumn{2}{|c|}{200.21} & \multicolumn{2}{|c|}{$6.37^{*}$} \\
\hline Gender X SES & 89.63 & 2 & \multicolumn{2}{|c|}{44.82} & \multicolumn{2}{|c|}{1.43} \\
\hline Error & 3584.12 & 114 & \multicolumn{2}{|c|}{31.43} & & \\
\hline \multicolumn{5}{|c|}{ Men } & \multicolumn{2}{|c|}{ Women } \\
\hline & High & Medium & Low & High & Medium & Low \\
\hline Mean & 17.43 & 17.36 & 15.59 & 20.11 & 20.78 & 15.65 \\
\hline SD & 3.62 & 3.59 & 2.76 & 4.57 & 3.86 & 3.22 \\
\hline
\end{tabular}

${ }^{* *} \mathrm{p}<.01,{ }^{*} \mathrm{P}<.05$

\section{Co relational analyses}

Arising from the above discussion, it observed that both gender and SES have significantly influenced the quality of life, measures of psychological well-being and depression. Hence, it is pertinent to understand the relationships among these constructs by carrying out co relational analyses. The correlation matrix for all the eight variables is presented in Table 9: Correlation Matrix for the eight variables including Quality of life, six measures of Psychological Well-being and Depression for 120 subjects.

\begin{tabular}{|c|c|c|c|c|c|c|c|c|}
\hline Variables & $\begin{array}{c}\text { Quality of } \\
\text { life }\end{array}$ & Autonomy & $\begin{array}{c}\text { Environmental } \\
\text { mastery }\end{array}$ & $\begin{array}{c}\text { Personal } \\
\text { growth }\end{array}$ & $\begin{array}{c}\text { Positive } \\
\text { relations }\end{array}$ & $\begin{array}{c}\text { Purpose of } \\
\text { life }\end{array}$ & $\begin{array}{c}\text { Self- } \\
\text { acceptance }\end{array}$ & $\begin{array}{c}\text { depression } \\
\text { Quality of life }\end{array}$ \\
\hline Autonomy & & $0.46^{* *}$ & $0.38^{* *}$ & $0.52^{* *}$ & $0.39^{* *}$ & $0.58^{* *}$ & $0.57^{* *}$ & $-0.44^{* *}$ \\
\hline $\begin{array}{c}\text { Environmental } \\
\text { mastery }\end{array}$ & & & $0.31^{* *}$ & $0.55^{* *}$ & $0.36^{* *}$ & $0.48^{* *}$ & $0.39^{* *}$ & 0.10 \\
\hline Personal growth & & & $0.62^{* *}$ & $0.38^{* *}$ & $0.46^{* *}$ & $0.57^{* *}$ & $-0.49^{* *}$ \\
\hline Positive relations & & & & & $0.37^{* *}$ & $0.52^{* *}$ & $0.61^{* *}$ & $-0.48^{* *}$ \\
\hline Purpose of life & & & & & & $0.32^{* *}$ & $0.55^{* *}$ & $-0.53^{* *}$ \\
\hline Self-acceptance & & & & & & & & \\
\hline
\end{tabular}

${ }^{* *} \mathrm{P}<.01$

On the other hand, depression is found significantly negatively related to quality of life. Hence it may be pointed out that quality of life is source of depression among the urban elderly and thus psychological wellbeing having promoted better quality of life can save elderly from depression. Further, five of the six measures of psychological wellbeing except the autonomy are also found to have significant negative correlations with depression to clearly indicate that these attributes of psychological wellbeing are safeguard against elderly depression.
Table 9. It is observed from the correlation that quality of life is significantly positively correlated with all the six measures of psychological wellbeing. Purpose in life, self-acceptance, and personal growth are found to very high correlations with quality of life there by suggesting that these three attributes are important in maintaining a good quality of life. Autonomy is also found as another important factor for quality of life. 
physicians to diagnose and manage depression among elderly. Data from India suggest that various psychosocial factors such as loneliness, poor social, family support, isolation, dependency, lack of family care and affection, insufficient time spent with children, stressful life events, perceived poor health, lower level of spirituality, and higher use of emotion-based coping increase the risk of depression among the elderly. Traditional joint family structure in India is on a downhill, and it is being replaced by nuclear families in the urban set up.

If one takes this into account along with the psychosocial factors associated with depression among elderly, it can be said that over the years there would be a significant rise in depression among the elderly. Hence, before such a scenario arises, there is a need to emphasize the importance of joint family structure and encourage people to follow the same. The lifestyle and dietary factors linked with depression suggest that there is a need to encourage geriatric patients to indulge in regular exercise, abstain from various substances including smoking, maintain regular dietary habits and develop hobbies to keep themselves occupied. In respect of the above discussion, the following relevant conclusions can be derived from the present study.

a. Women are more vulnerable to depression and it is found that attributes of psychological wellbeing are strong safeguards against depression. Hence, different psychosocial programs should be developed to enhance the psychological wellbeing of the elderly women in the urban localities.

b. In general, the quality of life of the urban elderly is not of a good standard. Provisions are to be created to provide better quality of for the urban elderly.

c. Urban elderly male are low in self acceptance. Further research need to be carried out to understand the reasons for this and appropriate measures should be taken to increase the self-acceptance of the elderly urban males. d. Autonomy as an attribute of psychological wellbeing is not found to be correlated with depression. It may be understood that they have willingly compromised with their children at the cost of their autonomy. Further study need to be carried to explain that behaviour of the urban elderly.

e. Over all, the study provided a basis for understanding the psychosocial aspects of the living conditions of the urban elderly which can provide the basis for providing different health services to them.

\section{References}

1. Ankur Barua, Mihir Kumar Ghosh, Nilamadhab Kar, Mary Anne Basilio (2011) Prevalence of depressive disorders in the elderly. Annals of Saudi Medicine 31(6): 620-624.

2. Beekman AT, Copeland JR, Prince MJ (1999) Review of community prevalence of depression in later. British Journal of Psychiatry 174: 307-311.

3. Chen R, Copeland JRM, Wei L (1999) A Meta-analysis of epidemiological studies in depression of older people in the People's Republic of China. International journal of Geriatric Psychiatry 14: 821-830.

4. Dhara RD, Jogsan YA (2013) Depression and psychological well-being in old age. Journal of Psychol Psychother 3(3): 117.

5. Global aging and health Wave-I study. WHO study on global Ageing and adult health (SAGE), SAGE data archive, UK.

6. Nandi DN, Ajmany S, Malhotra N (2002) Depression in elderly: A review of Indian Research. Journal of Psychiatry 42(4): 87-95.

7. Ramachandran VM, Sarada M, Arunagiri S (1982) Socio-cultural factors in late onset of Depression. Indian Journal of Psychiatry 24: 268-273.

8. Sagar SK, Grover S, Malhotra N (2002) Depression in elderly: A review of India. Research journal of Geriatric Mental Health 2(1): 4-15.

9. Satapthy R, Kar N, Das I, Kar Gopal Chandra, Pati T (1997) A study of major physical disorders among the elderly deoressives. Indian Journal of Psychiatry 39(4): 278-281.

10. Tiple Prashanth, SN Sharma, Srivastav AS (2006) Psychiatric morbidity in geriatric people. Indian Journal of Psychiatry 48(2): 88-94.

\section{Your next submission with Juniper Publishers will reach you the below assets}

- Quality Editorial service

- Swift Peer Review

- Reprints availability

- E-prints Service

- Manuscript Podcast for convenient understanding

- Global attainment for your research

- Manuscript accessibility in different formats

( Pdf, E-pub, Full Text, Audio)

- Unceasing customer service

Track the below URL for one-step submission https://juniperpublishers.com/online-submission.php 